\title{
Atrazine Sorption by Biochar, Tire Chips, and Steel Slag as Media for Blind Inlets: A Kinetic and Isotherm Sorption Approach
}

\author{
Javier M. Gonzalez ${ }^{1}$, Martin J. Shipitalo², Douglas R. Smith ${ }^{3}$, Elizabeth Warnemuende-Pappas ${ }^{1}$, \\ Stanley J. Livingston ${ }^{1}$
}

${ }^{1}$ USDA-ARS National Soil Erosion Research Laboratory, West Lafayette, IN, USA

${ }^{2}$ USDA-ARS National Laboratory for Agriculture and the Environment, Ames, IA, USA

${ }^{3}$ USDA-ARS Grassland, Soil and Water Research Laboratory, Temple, TX, USA

Email: *javier.gonzalez@ars.usda.gov

How to cite this paper: Gonzalez, J.M., Shipitalo, M.J., Smith, D.R., WarnemuendePappas, E. and Livingston, S.J. (2016) Atrazine Sorption by Biochar, Tire Chips, and Steel Slag as Media for Blind Inlets: A Kinetic and Isotherm Sorption Approach. Journal of Water Resource and Protection, 8, 1266-1282.

http://dx.doi.org/10.4236/jwarp.2016.813097

Received: September 13, 2016

Accepted: November 26, 2016

Published: November 29, 2016

Copyright $\odot 2016$ by authors and Scientific Research Publishing Inc. This work is licensed under the Creative Commons Attribution International License (CC BY 4.0).

http://creativecommons.org/licenses/by/4.0/

(c) †) Open Access

\begin{abstract}
Surface inlets are installed in subsurface drainage systems to reduce ponding duration and surface runoff, but can contribute to water quality concerns by allowing water to directly enter buried drains. Blind inlets consist of perforated pipes covered with gravel and are separated from an overlying sand layer by a geotextile membrane and have been shown to be more effective in reducing losses of sediment, nutrients, and pesticides than typical tile line risers. In this study, we investigated whether the effectiveness of blind inlets to sorb pollutants, with emphasis on the herbicide atrazine, could be further improved by amended them with materials other than limestone. The media, shredded tires (tire chips), electric arc steel furnace slag (steel slag), and oak-derived biochar were chosen because they are readily available, inexpensive, and do not present environmental concerns. Kinetic sorption and isotherms were determined to ascertain atrazine sorption by these materials, in addition to testing for potential metal leaching using the Synthetic Precipitation Leaching Procedure (SPLP) and the Toxicity Characteristic Leaching Procedure (TCLP). The kinetic data were fitted using pseudo first- and second-order reaction equations and indicated that atrazine sorption rate was 38 times faster and equilibrium was reached 5 times earlier for biochar than tire chips. The 24-h sorption isotherm data were fitted to the Freundlich sorption equation. The sorption coefficient for biochar was higher than for tire chips, steel slag, and limestone. Per the SPLC and TLCP tests, there was no leaching of heavy metals at levels of environmental concern. Our results suggested that the effectiveness of blind inlets as well as other conservation practices that include filter media such as rain gardens and filter socks could be improved by incorporating more reactive materials than sand and gravel with biochar being a particularly effective alternative.
\end{abstract}




\section{Keywords}

Atrazine, Biochar, Shredded Tires, Sorption, Water Quality

\section{Introduction}

The Conservation Effects Assessment Project (CEAP) is a U.S. Department of Agriculture multi-agency effort to evaluate the environmental benefits of conservation practices and to develop new and/or modify the existing ones to manage the agricultural landscape for environmental stewardship. These conservation practices include reduced tillage, nutrient management, buffer strips, and drainage water management, among others.

Fields with subsurface drainage systems and prolonged standing water in depressional areas can drastically reduce crop yields. This concern can be partially alleviated by installing surface inlets that reduce the duration of ponding [1]. Unfortunately, these inlets provide an open conduit for surface water to enter subsurface drains, and thus can contribute to water quality concerns. Blind inlets are a relatively new conservation practice designed to replace surface inlets and reduce these concerns while maintaining high infiltration rates. They are infiltration galleries constructed by covering perforated drainage pipes with gravel followed by a geotextile membrane and topped with a layer of sand. Blind inlets have added benefits, compared to traditional tile risers (vertical perforated pipes) including reduced sediment losses and farming operations can be conducted over the blind inlets, including tillage, planting, and harvesting [2]. Moreover, blind inlets, compared to tile risers, have been shown to reduce annual losses of phosphate-P (up to $72 \%$ ), ammonium-N (up to $59 \%$ ), nitrate-N (up to $24 \%$ ) [2] [3]; and herbicides including atrazine (up to $82 \%$ ), metolachlor (up to $80 \%$ ), 2,4-D (up to $81 \%$ ), and glyphosate (up to $72 \%$ ) [4].

The effectiveness of blind inlets, compared to tile risers, in reducing sediment, nutrient, and pesticide losses is attributed to the tortuosity created by the fill material (typically readily available limestone) and the accumulation of sediments, which may serve as sorption sites for nutrients and pesticides [2] [4]. The lifespan of blind inlets is unknown; however, blind inlets in small-farmed closed depressions in Northeast Indiana were installed in 2005, and they are still functioning after more than ten years [2] [4]. Even though the current designs of blind inlets are effective at reducing sediment and pollutant losses from surface runoff, replacing some of the limestone, a sedimentary rock composed mainly of $\mathrm{CaCO}_{3}$, with stronger sorbents such as scrap tires, biochar, and steel slag might enhance their performance.

About $3.47 \times 10^{6} \mathrm{Mg}$ of scrap tires were generated in 2013 in the U.S., of which 2.97 $\times 10^{5} \mathrm{Mg}$ were disposed of in landfills [5]. Scrap tires have shown to be effective sorbents of heavy metals [6] [7], aromatic hydrocarbon compounds [8] [9]; and pesticides [10]. Tires are constructed using textile, steel, and rubber with the type and amount of each component dependent on the manufacturer and tire usage [11]. The rubber com- 
posites are made of synthetic and natural rubber and reinforcing materials that include carbon black [9] [12], which may be a key component for the sorption of aromatic compounds.

Biochar is a carbonaceous material produced from feedstock pyrolysis in low oxygen environments. The chemical and physical properties of biochars are dependent on feedstock type and pyrolysis conditions. As pyrolysis temperatures increase, feedstock characteristics are diminished, and biochar resembles condensed carbonaceous matter [13]. As a soil amendment, biochar can improve chemical and physical properties of unproductive, dystrophic soils [13] [14]. Another benefit is that biochar sorbs inorganic and organic compounds of environmental concern, including heavy metals and pesticides [15] [16] [17] [18]. Biochar is currently available in small batches, but it may be available in large quantities as a byproduct of biofuel production if this industry thrives in the future.

Electric arc steel furnace slag (steel slag) is a byproduct of the smelting of iron ore to produce steel. Steel slag is composed mostly of oxides of $\mathrm{Ca}$, Fe, and Al. Steel slag is currently being studied as a blind inlet bed material to remove soluble $\mathrm{P}$ from surface runoff.

Atrazine, a pre- and post-emergence herbicide to prevent broadleaf weeds in corn (Zea mays), is the second most used herbicide in corn; in the U.S. Midwest, 12,271 Mg were applied in 2014 [19]. Atrazine off-transport to streams is of environmental concern since concentrations can exceed both aquatic life benchmarks [20] and threshold levels in drinking water supplies [21]. Atrazine is the most frequently detected pesticide in agricultural streams [22]. Thus, readily available material that sorbs specific compounds (e.g. atrazine) may be valuable as an alternative or add-on to the limestone to enhance the blind inlet potential to reduce losses of pollutants that otherwise may end up in streams. These alternative materials should not pose environmental concerns when used in the field, e.g. leaching of other pollutants.

In this study, we investigated atrazine sorption by tire chips, steel slag, and biochar that could be used in the blind inlet as bed materials. In addition, we measured their potential to leach other contaminants using standard protocols to ensure that their usage does not result in environmental concerns.

\section{Materials and Methods}

\subsection{Media}

The tire chips (Entech, White Pigeon, MI, USA) were $\sim 2 \times 4 \mathrm{~cm}$ in size and included a mixture of $\sim 50 \%$ "tire chips with fabric" (cross woven pieces of fabric exposed on edges of the tire chip), $25 \%$ "layered tire chips" (layers of exposed fabric, less than $5 \mathrm{~mm}$ in length), $20 \%$ "tire chips with metal" (metal pieces exposed), and $~ 5 \%$ "rubber tire chips" (no secondary material exposed). The steel slag, produced at Nucor Steel (Crawfordsville, IN, USA) and provided by Edward C. Levy Co. (Dearborn, MI, USA), ranged from 0.75 to $1.25 \mathrm{~cm}$ in length and the mineral composition included larnite $\left(\mathrm{Ca}_{2} \mathrm{SiO}_{4}\right)$, srebrodolskite $\left(\mathrm{Ca}_{2} \mathrm{Fe}_{2} \mathrm{O}_{5}\right)$, brownmillerite $\left(\mathrm{Ca}_{2} \mathrm{AlFeO}_{5}\right)$, wuestite (FeO with 
$\mathrm{MgO}$ and $\mathrm{MnO})$, gehlenite $\left(\mathrm{Ca}_{2} \mathrm{Al}_{2} \mathrm{SiO}_{7}\right)$, and bredigite $\left(\mathrm{Ca}_{7} \mathrm{Mg}\left(\mathrm{SiO}_{4}\right)_{4}\right)$ [23]. The limestone (Hanson Aggregates, Fort Wayne, IN, USA) ranged from 0.75 to $1.25 \mathrm{~cm}$. The biochar (Buy Activated Charcoal, Crawford, NE, USA), was derived from oak (Quercus spp.) and pyrolyzed at $425^{\circ} \mathrm{C}$ with a particle size of 0.5 to $1 \mathrm{~cm}$. Each material, except biochar, was triple rinsed in deionized (D.I.) water to remove any fines and allowed to air dry (Figure 1).

\subsection{Sorption Studies}

\subsubsection{Kinetic Sorption Studies}

Kinetic studies were conducted only for the tire chips and biochar. A $10 \mu \mathrm{g} \cdot \mathrm{L}^{-1}$ solution of atrazine (prepared in $0.01 \mathrm{M} \mathrm{CaCl}_{2}$ ) was added to biochar (1:32 biochar/atrazine solution ratio, $\mathrm{w} / \mathrm{w}$ ) or tire chips (1:5 tire chips/atrazine solution ratio, $\mathrm{v} / \mathrm{v}$ ) and shaken at room temperature in a reciprocal shaker. The different sorbent/solution ratios were employed due to the small quantities of biochar available for the experiment (compared to the tire chips). Subsamples from the biochar experiment were withdrawn at 1, 2, 3, 4, $6,8,10,12,14,18,22$, and 26 hours; whereas from the tire chips subsamples were withdrawn at $1,2,3,4,6,8,10,12,24$, and 28 hours, filtered through $0.45 \mu \mathrm{m}$ nylon filters and refrigerated at $4{ }^{\circ} \mathrm{C}$ prior to atrazine analysis. Three replicates were run for each material.

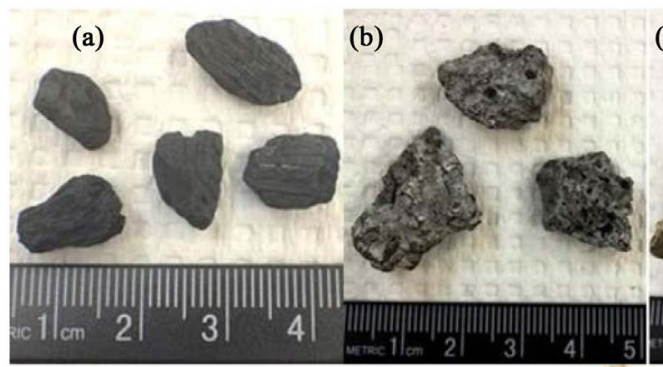

(c)

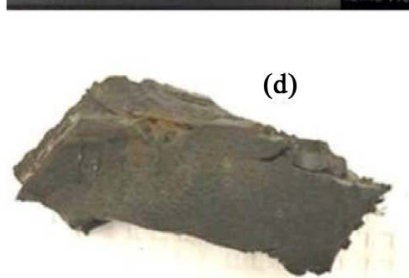

(e)
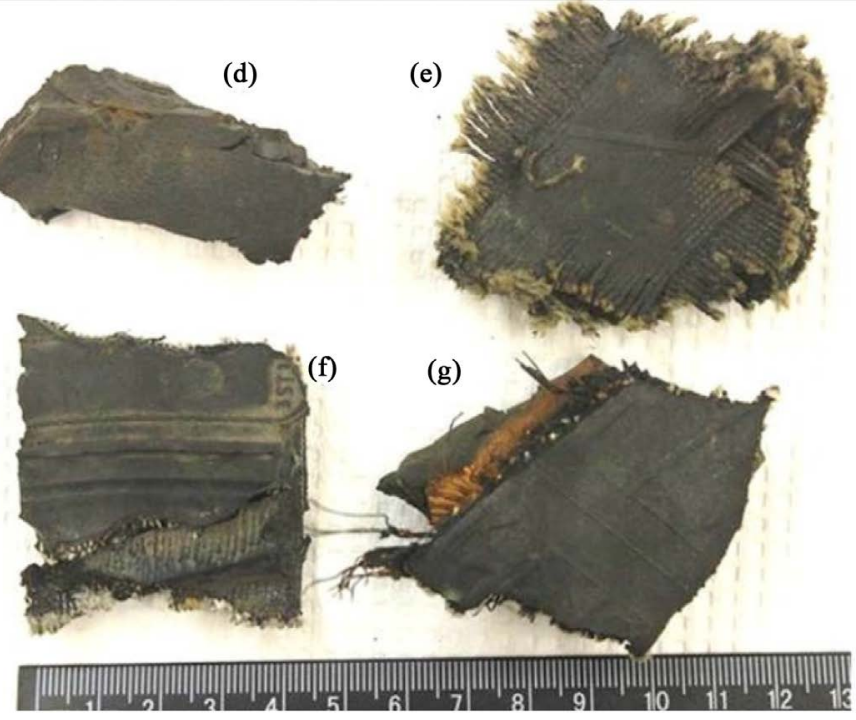

Figure 1. Material used in this study; (a) biochar; (b) steel slag; (c) limestone; and (d) rubber tires chips; (e) tire chips with fabric; (f) layered tire chips; and (g) tire chips with metal. 


\subsubsection{Sorption Isotherm Studies}

About $100 \mathrm{~cm}^{3}$ of tire chips, limestone, or steel slag and $300 \mathrm{~mL}$ of $0.01 \mathrm{M} \mathrm{CaCl}_{2}$ (or D.I. water for limestone and steel slag) for were placed into 1-L HDPE containers and pre-equilibrated using a gyratory shaker at $100 \mathrm{rpm}$ overnight. After pre-equilibration, $\mathrm{pH}$ of the solutions was measured, and the solution was decanted. Atrazine solutions, prepared in $0.01 \mathrm{M} \mathrm{CaCl}_{2}$ (or D.I. water for limestone and steel slag) to target a total concentration of $0,3,15,30,150,300$ and $1500 \mu \mathrm{g} \cdot \mathrm{L}^{-1}$ of atrazine at a $1: 5$ material/solution ratio $(\mathrm{v} / \mathrm{v})$, were added to the sorbing materials and shaken on a gyratory shaker at $100 \mathrm{rpm}$ for 24 hours. After the sorption step, the samples were analyzed for $\mathrm{pH}$, filtered through $0.45 \mu \mathrm{m}$ nylon filters, and refrigerated at $4^{\circ} \mathrm{C}$ before atrazine analysis. For the desorption step, $500 \mathrm{~mL}$ of $0.01 \mathrm{M} \mathrm{CaCl}_{2}$ was added to the samples after the sorption step and shaken at $100 \mathrm{rpm}$ for 24 hours on a gyratory shaker. The supernatant was analyzed for $\mathrm{pH}$, filtered through $0.45 \mu \mathrm{m}$ nylon filters, and refrigerated at $4^{\circ} \mathrm{C}$ before atrazine analysis. For the biochar, atrazine solutions prepared in $0.01 \mathrm{M}$ $\mathrm{CaCl}_{2}$ and biochar (1:32 biochar/atrazine solution ratio, w/w) were shaken for 24 hours at room temperature in a reciprocal shaker to target $5,10,50$ and $100 \mu \mathrm{g} \cdot \mathrm{L}^{-1}$ of atrazine, filtered through $0.45 \mu \mathrm{m}$ nylon filters, and refrigerated at $4^{\circ} \mathrm{C}$ prior to atrazine analysis. Three replicates were used for each material and concentration level.

\subsubsection{Atrazine Sorption by Dry and "Pre-Wetted" Tire Chips}

During long periods without rain, the blind inlet bed material becomes dry; thus, a study was conducted to determine if the "wetting" state of the tire chips affected atrazine sorption. About $100 \mathrm{~cm}^{3}$ of mixed tire chips and $400 \mathrm{~mL}$ of $0.01 \mathrm{M} \mathrm{CaCl}_{2}$ solution were placed in 1-L HDPE bottles and pre-equilibrated overnight ("pre-wetted" state) on a gyratory shaker at $100 \mathrm{rpm}$. After pre-equilibration, $100 \mathrm{~mL}$ of atrazine were added, to yield final concentrations of 50 and $100 \mu \mathrm{g} \cdot \mathrm{L}^{-1}$, and shaken on a gyratory shaker at $100 \mathrm{rpm}$ for 24 hours. For the "dry" state, about $100 \mathrm{~cm}^{3}$ of dry tire chips $+500 \mathrm{~mL}$ of 50 or $100 \mu \mathrm{g} \cdot \mathrm{L}^{-1}$ atrazine were added in 1-L HDPE bottles and shaken on a gyratory shaker at $100 \mathrm{rpm}$ for 24 hours. For both the "pre-wetted" and "dry" states, after the sorption step, a sub-sample was filtered through a $0.45 \mu \mathrm{m}$ nylon filter and refrigerated at $4^{\circ} \mathrm{C}$ before atrazine analysis. The remainder of the supernatant was decanted. For the desorption step, $500 \mathrm{~mL}$ of $0.01 \mathrm{M} \mathrm{CaCl}_{2}$ were added to the tire chips and shaken for 24 hours at room temperature. After 24 hours, the samples were filtered through $0.45 \mu \mathrm{m}$ nylon filters and refrigerated at $4^{\circ} \mathrm{C}$ before atrazine analysis. Three replicates were used for each concentration level.

\subsection{Atrazine Analysis}

Samples were analyzed for atrazine using gas or liquid chromatography. Samples from biochar and tire chip sorption experiments were analyzed using a gas chromatography system equipped with a mass spectrometer detector [24]. Samples from the steel slag, limestone, and the "pre-wetted vs. dry" experiments were analyzed using an ultra-performance liquid chromatography system equipped with tandem mass spectrometer detectors [4]. 


\subsection{Sorption Parameters}

The kinetic sorption data was fitted to the pseudo first- and second-order reaction models. Pseudo kinetic reaction models are used to fit experimental kinetic data from liquid-solid interfaces [25]. The sorption rate under the pseudo first-order reaction equation is stated as [26]:

$$
\frac{\partial q_{t}}{\partial t}=k_{1}\left(q_{e}-q_{t}\right)
$$

where $q_{e}$ is the amount sorbed at equilibrium $\left(\mu \mathrm{g} \cdot \mathrm{kg}^{-1}\right), q_{t}$ is the amount sorbed at time $t\left(\mu \mathrm{g} \cdot \mathrm{kg}^{-1}\right)$, and $k_{1}$ is the pseudo first-order reaction $\left(\mathrm{min}^{-1}\right)$. Integration of Equation (1) under the conditions $q_{t}=0$ at $t=0$ and $q_{t}=q_{t}$ at $t=t$.

$$
q_{t}=q_{e}\left(1-\mathrm{e}^{\left(-k_{1} t\right)}\right)
$$

The "Exponential Rise to Maximum equation, Single, 2 Parameter" nonlinear regression $y=a\left(1-\mathrm{e}^{-b x}\right)$ in SigmaPlot 11 (Systat Software, Inc., San Jose, CA) was used to as equivalent to Equation (2) to fit the experimental data [26].

The pseudo second-order reaction model is written as:

$$
\frac{\partial q_{t}}{\partial t}=k_{2}\left(q_{e}-q_{t}\right)^{2}
$$

where $k_{2}$ is the pseudo second-order rate constant $\left(\mu \mathrm{g} \cdot \mathrm{kg}^{-1} \cdot \mathrm{min}^{-1}\right)$. Integration of Equation (3) gives [26]:

$$
q_{t}=\frac{q_{e}^{2} k_{2} t}{1+k_{2} q_{e} t}
$$

The "Hyperbola equation, Single Rectangular, 2 Parameter" nonlinear regression from SigmaPlot 11 is given by:

$$
y=\frac{a x}{b+x}
$$

Thus, Equation (4) can be rearranged to Equation (5):

$$
q_{t}=\frac{q_{e} t}{\frac{1}{k_{2} q_{e}}+t}
$$

The sorption data was fitted to the Freundlich equation:

$$
S=K_{f} C^{(1 / n)}
$$

where $S$ is the sorption $\left(\mathrm{mg} \cdot \mathrm{kg}^{-1}\right), C$ is the equilibrium concentration $\left(\mathrm{mg} \cdot \mathrm{L}^{-1}\right)$, and the dimensionless $K_{f}$ is the sorption parameter, and $n$ is a linearity parameter [27].

\subsection{Leachability Studies}

To investigate the leachability of metals of environmental concern from tire chips, steel slag, and limestone used in this study, we used the US EPA 1312 procedure Synthetic Precipitation Leaching Procedure (SPLP) [28] and 1311 Toxicity Characteristic Leaching Procedure (TCLP) [29]. The SPLP test is used to simulate in-situ leaching from the 
testing material under synthetic precipitation, whereas the TCLP is used to simulate leaching under landfill conditions. Briefly, $25 \mathrm{~g}$ of sample was combined with $500 \mathrm{~mL}$ of SPLP ( $\mathrm{pH} 4.2$ ) or TCLP solutions and shaken on a reciprocal shaker at $90 \mathrm{rpm}$ for 24 hours. A $20 \mathrm{~mL}$ sample was removed for $\mathrm{pH}$ evaluation, and the remaining solution was filtered using a $0.45 \mu \mathrm{m}$ nylon filter and refrigerated at $4^{\circ} \mathrm{C}$ before metal analysis using a Perkin-Elmer Optima 8300 inductively coupled plasma optical emission spectrometer system (Waltham, MA).

\section{Results and Discussion}

\subsection{Kinetic Studies}

The data from the kinetic sorption studies for the biochar and tire chips were well fitted to the pseudo first- and second-order reaction models (Figure 2). The correlation coefficients for each model, however, were higher for biochar than for tire chips indicating a better fit for biochar. Within materials, the correlation coefficients for the pseudo

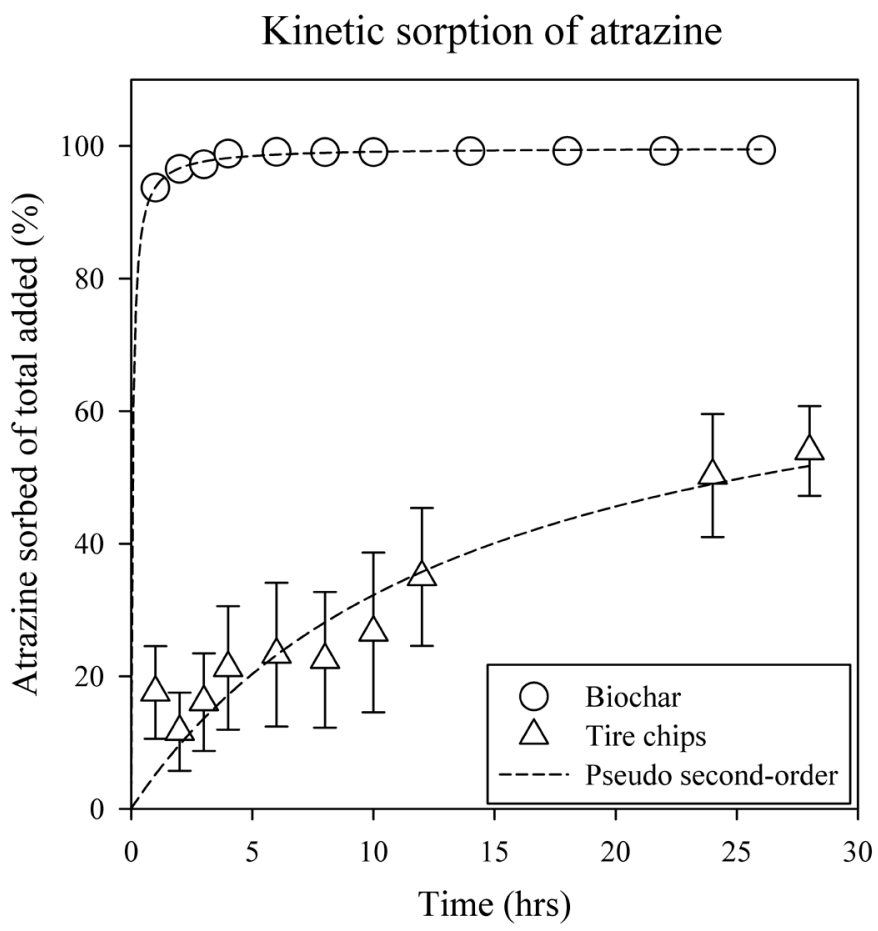

Sorption kinetic parameters and correlation coefficients for nonlinear regressions for the atrazine sorption by tire chips and biochar used in this experiment.

\begin{tabular}{lccccccc}
\hline & \multicolumn{3}{c}{ Pseudo first-order } & & \multicolumn{3}{c}{ Pseudo-second-order } \\
\cline { 2 - 3 } \cline { 6 - 7 } Material & $k_{1}\left(\mathrm{~h}^{-1}\right)$ & $q_{e}\left(\mu g \mathrm{~kg}^{-1}\right)$ & $\mathrm{r}^{2}$ & & $k_{2}\left(\mathrm{~kg} \mu g^{-1} \mathrm{~h}^{-1}\right)$ & $q_{e 2}\left(\mu g \mathrm{~kg}^{-1}\right)$ & $\mathrm{r}^{2}$ \\
\hline \multirow{2}{*}{ Tire Chips } & 0.08 & 25.22 & 0.846 & & $2.08 \times 10^{-3}$ & 33.87 & 0.863 \\
Biochar & 3.08 & 292.8 & 0.997 & & $5.54 \times 10^{-2}$ & 295.8 & 0.999 \\
\hline
\end{tabular}

Figure 2. Measured cumulative sorption of atrazine by biochar and tire chips as a function of time fitted to pseudo first- and second-order models. Error bars represent the results of three replications. 
first- and second-order reaction models were similar (Figure 2), suggesting that either model can be used. The rate of sorption was $\sim 38$ times faster for biochar than the tire chips and equilibrium was reached in $\sim 6$ hours compared to $\sim 30$ hours (as calculated from by the first-order kinetic model) for tire chips. In the first hour, $97 \%$ of the atrazine was sorbed by the biochar and after 6 hours, $99 \%$ of atrazine was removed from the solution. In comparison, tire chips removed only $18 \%$ and $23 \%$ after 1 and 6 hours, respectively. After 24 hours, tire chips removed $50 \%$ of the atrazine from solution.

The kinetic sorption of organic compounds on porous materials is governed by fast and slow sorption steps, indicative of surface sorption and pore-diffusion processes, respectively [30]. Thus, plotting kinetic sorption data provides information on the sorption processes. With biochar, fast atrazine sorption occurred within two hours, followed by slow sorption. For the tire chips, atrazine sorption rate decreased with time as observed by the convex curve (Figure 2 ). Given the fact that $>93 \%$ of atrazine sorption by biochar occurred during the first hour the data suggested that surface sorption was the dominant process whereas atrazine sorption by tire chips may have been controlled by both surface sorption and pore-diffusion processes.

Reports on kinetic sorption of atrazine by biochar and tire chips are scarce. Gupta and coworkers [31] using activated charcoal prepared from waste rubber tire, reported that a pseudo first-order reaction model explained atrazine sorption kinetics better than a pseudo second-order model. Their pseudo first-order rate constants (i.e. $k_{1}$ values) were, 5.59 and $3.65 \mathrm{~h}^{-1}$, for initial atrazine concentrations of 5 and $12 \mathrm{mg} \cdot \mathrm{L}^{-1}$, respectively. These values are similar to the calculated $k_{1}$ value in our study, $3.08 \mathrm{~h}^{-1}$ for biochar. Conversely, for atrazine sorption kinetics by granulated activated carbon and carbon nanotubes using atrazine concentrations of 1 and $30 \mathrm{mg} \cdot \mathrm{L}^{-1}$, the $k_{1}$ and secondorder reaction rate constant $\left(k_{2}\right)$ values ranged from 0.038 to $0.042 \mathrm{~h}^{-1}$ and from $8.00 \times$ $10^{-9}$ to $1.89 \times 10^{-7} \mathrm{~kg} \cdot \mu \mathrm{g} \cdot \mathrm{h}^{-1}$, respectively [30]. In a biochar-amended soil ( $\left.1 \% \mathrm{w} / \mathrm{w}\right)$, using an initial concentration of $5 \mathrm{mg} \cdot \mathrm{L}^{-1}$ atrazine, the $k_{2}$ values ranged from $3.11 \times 10^{-5}$ to $7.46 \times 10^{-5} \mathrm{~kg} \cdot \mu \mathrm{g} \cdot \mathrm{h}^{-1}$, and the amount sorbed at equilibrium was dependent on the biochar used [32]. Biochars produced at higher temperatures reached equilibrium faster than biochars produced at lower temperatures [31]. In our study, we used an initial atrazine concentration of $10 \mu \mathrm{g} \cdot \mathrm{L}^{-1}$ to reflect concentrations typically observed in surface runoff water. Conversely, the above-cited studies used initial atrazine concentrations ranging from 1 to $30 \mathrm{mg} \cdot \mathrm{L}^{-1}$ with a variety of sorbents (biochar, activated carbon, and carbon nanotubes). This probably contributed to the differences in the rate constant values we calculated and those reported in these studies.

Alam and coworkers [33] studied atrazine sorption kinetics for scrap tire granules (size $\sim 0.15$ to $0.30 \mathrm{~mm}$ ) and observed that the pseudo-first order $k_{1}$ values ranged from 0.72 to $0.81 \mathrm{~h}^{-1}$ and increased slightly with initial atrazine concentrations of 0.5 to 7.5 $\mathrm{mg} \cdot \mathrm{L}^{-1}$. Furthermore, from $84 \%$ to $88 \%$ of the atrazine in solution (initial concentration 0.5 or $1.0 \mathrm{mg} \cdot \mathrm{L}^{-1}$, respectively) was removed with only three-hour shaking [34]. The higher $k_{1}$ values obtained by these authors, compared to the tire chips in our study, 0.08 $\mathrm{h}^{-1}$, may be explained by the size of the material. In our study, tire chips measured from 
2 to $4 \mathrm{~cm}$ in size (Figure 1); whereas Alam and coworkers used rubber granules that were 67 to 267 times smaller in size. As a general rule, surface area increases as the material size decreases; thus, more sorption sites available and the faster the kinetic sorption.

\subsection{Sorption Isotherms}

Sorption studies were conducted by using about $100 \mathrm{~cm}^{3}$ of tire chips, limestone, and steel slag. The particle density of these materials was different with tire chips at 1.10 $\mathrm{g} \cdot \mathrm{cm}^{-3}$, limestone $2.43 \mathrm{~g} \cdot \mathrm{cm}^{-3}$, steel slag $3.51 \mathrm{~g} \cdot \mathrm{cm}^{-3}$ and with biochar at only 0.67 $\mathrm{g} \cdot \mathrm{cm}^{-3}$. Therefore, the Freundlich sorption parameters were calculated based on the mass of the materials instead of volume. Based on the Freundlich parameters (Table 1), atrazine sorption was highly dependent on sorbent type (Figure 3). Biochar was considerably more effective in removing atrazine in solution than the tire chips, limestone, and steel slag.

Atrazine has a high affinity to sorb on biochar with the extent of the sorption dependent on several factors including feedstock type and pyrolysis conditions [18] [35] [36]. Higher $K_{f}$ values for biochar were obtained in our study, $\log K_{f}=6.79$, than those in the literature, $\log K_{f}$ from 2.25 to 3.15 , using biochars derived at $450^{\circ} \mathrm{C}$ from trees, corncob, or corn straw [18] [35] [36]. The reasons for our higher sorption parameters are uncertain; however, we used lower initial concentrations of atrazine (compared to 0.05 to 30 $\mathrm{mg} \cdot \mathrm{L}^{-1}$ in the cited studies), which may contribute to the faster equilibrium. The specific details of the biochar used in our experiment are unknown; however, this biochar is used for filtration (Buyactivatedcharcoal.com), which may suggest that the biochar has low ash content and high surface area; thus, increasing pore volume and sorption sites.

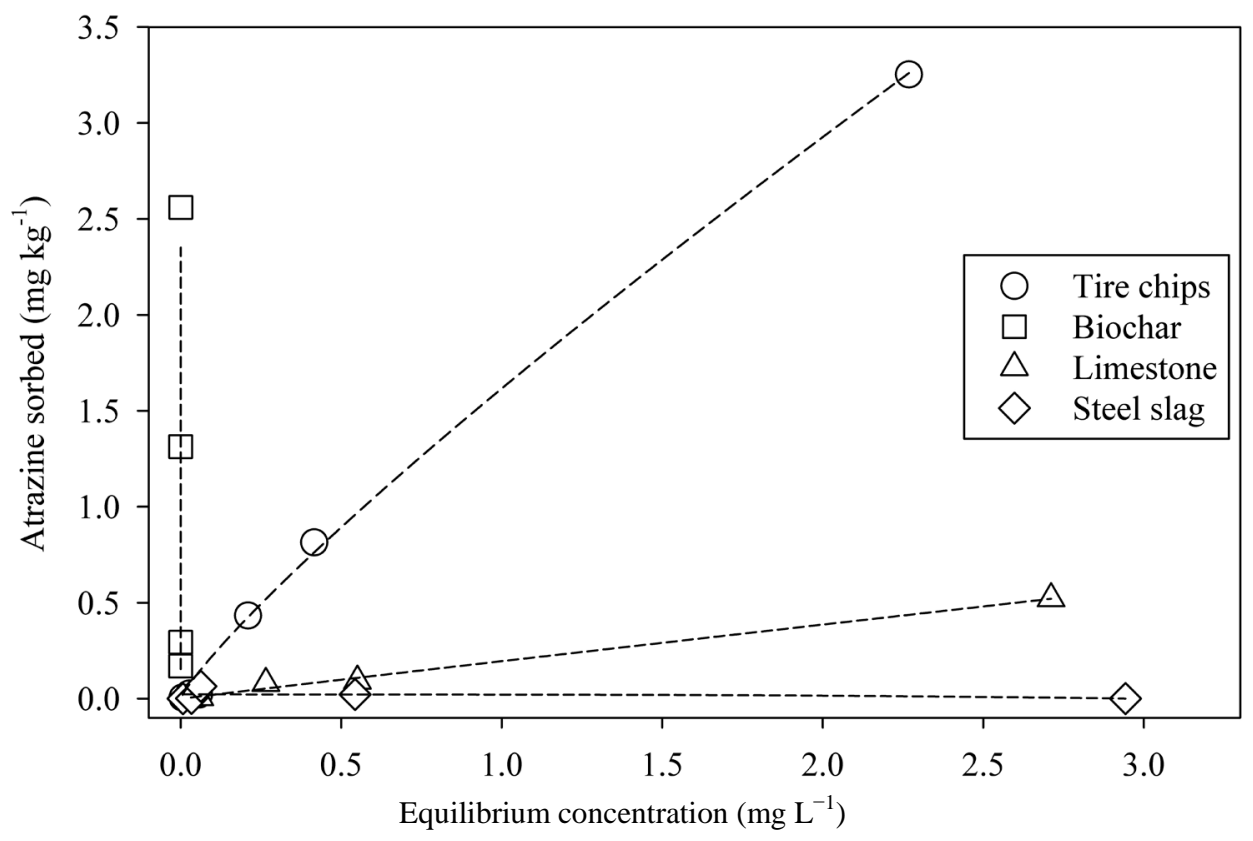

Figure 3. Sorption isotherms of atrazine by biochar, tire chips, steel slag, and limestone. 
The high sorptivity of atrazine by biochars is influenced by their chemical properties. Biochar produced above $350^{\circ} \mathrm{C}$ has lower $\mathrm{H} / \mathrm{C}$ ratios and higher aromatic moieties than those pyrolyzed at lower temperatures [37] and its surface exhibits hydrophobic (aromatic moieties), acidic (carbonyl groups), and basic (pyrenes and chromenes) properties due to the incomplete thermal decomposition and complexity of the feedstocks [38]. Accordingly, and considering the high atrazine sorption by biochar and their chemical properties; then, it is reasonable to suggest that several sorption mechanisms, including $\pi-\pi$ interactions and hydrogen bonding, are involved. Several mechanisms have been shown to be operative in atrazine sorption to carbon including $\pi-\pi$ interactions [39], hydrogen bonding (as both bond acceptor and donor), and van der Waals interactions [40].

The lower $K_{f}$ value for the tire chips, compared to biochar, was not surprising given that biochar surface area was higher due to its smaller particle size and the chemical characteristics of both sorbents. In our study, $42 \%$ of the initial atrazine concentration was removed by tire chips during the sorption step (Table 1). From $83 \%$ and $96 \%$ of the atrazine initial concentrations (ranging from 0.5 to $7.5 \mathrm{mg} \cdot \mathrm{L}^{-1}$ ) were removed by rubber granules from waste tires and wood charcoal, respectively [41]. The differences in the size of the tire chips and type of material may have contributed to the lower sorption capacity in our study compared to the $0.15-0.30 \mathrm{~mm}$ size rubber granules used by Alam and coworkers [41]. In our study, the tire chips were a mix of different shapes and physical appearance and composition (Figure 1).

The calculated Freundlich sorption coefficients of atrazine sorption by limestone and steel slag were low (Table 1). These findings were not surprising giving the fact that these materials have poor affinity for organic compounds, including pesticides [42]. The affinity of atrazine to river sediments (with $\sim 13 \% \mathrm{CaCO}_{3}$ ) was attributed primarily to the organic matter in the sediments [43]. Likewise, soils with high carbonate content $\left(>53 \% \mathrm{CaCO}_{3}\right)$ also showed low atrazine sorption [44]. Although blind inlets constructed with limestone bed material reduced the losses of atrazine and other pesticides, compared to the tile riser; this reduction was attributed to several factors, including reduced discharge rate, increased tortuosity, and the accumulation of sediments and soil organic carbon in the blind inlet bed [4].

Table 1. Atrazine Freundlich sorption parameters for the media used in this study.

\begin{tabular}{cccccccc}
\hline \multirow{2}{*}{ Material } & $\mathrm{pH}^{\mathrm{a}}$ & $\log \mathrm{K}_{\mathrm{f}}$ & $1 / \mathrm{n}$ & $\mathrm{r}^{2 \mathrm{~b}}$ & Sorption $^{\mathrm{c}}$ & Desorption $^{\mathrm{c}}$ & Net sorption $^{\mathrm{c}}$ \\
\cline { 6 - 8 } & & & & & & $\%$ & \\
\hline Biochar & $8.6 \pm 0.2$ & 6.79 & 1.79 & 0.978 & 99 & 0 & 99 \\
Tire Chips & $6.4 \pm 0.1$ & 0.19 & 1.14 & 0.950 & 42 & 21 & 21 \\
Limestone & $7.7 \pm 0.1$ & -0.69 & 1.34 & 0.953 & 6.7 & 0.4 & 6.3 \\
Steel slag & $9.6 \pm 0.1$ & -0.85 & 0.98 & 0.830 & 0.6 & 0.3 & 0.3 \\
\hline
\end{tabular}

${ }^{\mathrm{a}} \mathrm{pH}$ of the supernatant after the sorption step; ${ }^{\mathrm{b}}$ Regression coefficient between the experimental and the calculated

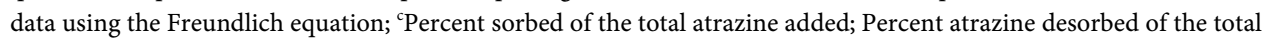
sorbed; Net sorbed $=$ Sorbed - Desorbed. 
The lowest sorption capacity for atrazine was observed with the steel slag (Table 1). The steel slag derived from electric-arc-furnace steelmaking is composed mainly of Ca and $\mathrm{Al}$ oxides [23]. The extent of atrazine sorption by oxides is $\mathrm{pH}$ dependent, as $\mathrm{pH}$ decreases, atrazine sorption increases [40]. The solution $\mathrm{pH}$ was 9.6 after the sorption step when steel slag was used. When biochar was used as a sorbent, the $\mathrm{pH}$ solution was 8.6; yet, atrazine sorption was much greater than observed with steel slag (Table 1). These observations confirm the importance of materials with organic moieties, mainly those with hydrophobicity character such as biochar. At $\mathrm{pH}$ ranging from 4 to 8 , atrazine sorption was insignificant by $\mathrm{Fe}$ oxides and smectites, whereas humic acid sorbed significant amounts of atrazine [45].

\subsection{Desorption Step}

The percent atrazine desorbed by $0.01 \mathrm{M} \mathrm{CaCl}_{2}$ is presented in Table 1 . No atrazine desorption was detected from biochar; whereas of the total atrazine sorbed $6 \%$ was desorbed from limestone, and 50\% was desorbed from tire chips and steel slag. This suggested that atrazine was irreversible sorbed by biochar and moderately sorbed by tire chips. Biochar amendments to soils reduced weed control by atrazine up to $75 \%$ [46], suggesting that biochar is an effective sorbent for atrazine when added to the soil. The low desorption from limestone, and perhaps steel slag, may have been due to the low overall amount of atrazine sorbed by these materials.

\subsection{Atrazine Sorption by Dry and Pre-Wet Tire Chips}

During drought periods, the blind inlet bed material may dry out; thus, a sorption-desorption study was conducted to assess the functionality of dried shredded tires to sorb atrazine. Compared to pre-wet shredded tires, $21 \%$ less sorption and $25 \%$ more desorption of atrazine (38\% less net atrazine sorption) were observed with the dry tire chips than with tire chips pre-equilibrated with $0.01 \mathrm{M} \mathrm{CaCl}_{2}$. The sorption/desorption from this experiment for both dry and pre-wet conditions appears to follow the same trend, i.e. desorption after sorption was similar as perceived from plotting the sorption and desorption data (Figure 4). The mechanisms leading to the greater sorption/desorption behavior by the dry tire chips, compared to the pre-wet tire chips, is unknown. Atrazine may slowly diffuse into micropores and fissures in dry tire chips, and consequently, reduce sorption due to lack of a "pre-equilibrium step" before the atrazine addition. Slow diffusion processes, including "organic matter diffusion" and "sorption-retarded pore diffusion" describe slow sorption and desorption hysteresis of organic compounds into/from complex matrices [47].

\subsection{Sorbent Leaching Properties}

The concentrations of leachates from the sorbents used in this experiment are listed in Table 2. The leaching potential of biochar was not evaluated since wood-based biochar usually does not contain large amounts of heavy metals of environmental concern [48]. The SPLP test is used to simulate the movement of inorganic phases under acidic 
Table 2. Leachate concentrations from the isotherm sorption media using SPLC (Synthetic Precipitation Leaching Procedure) and TCLP (Toxicity Characteristic Leaching Procedure).

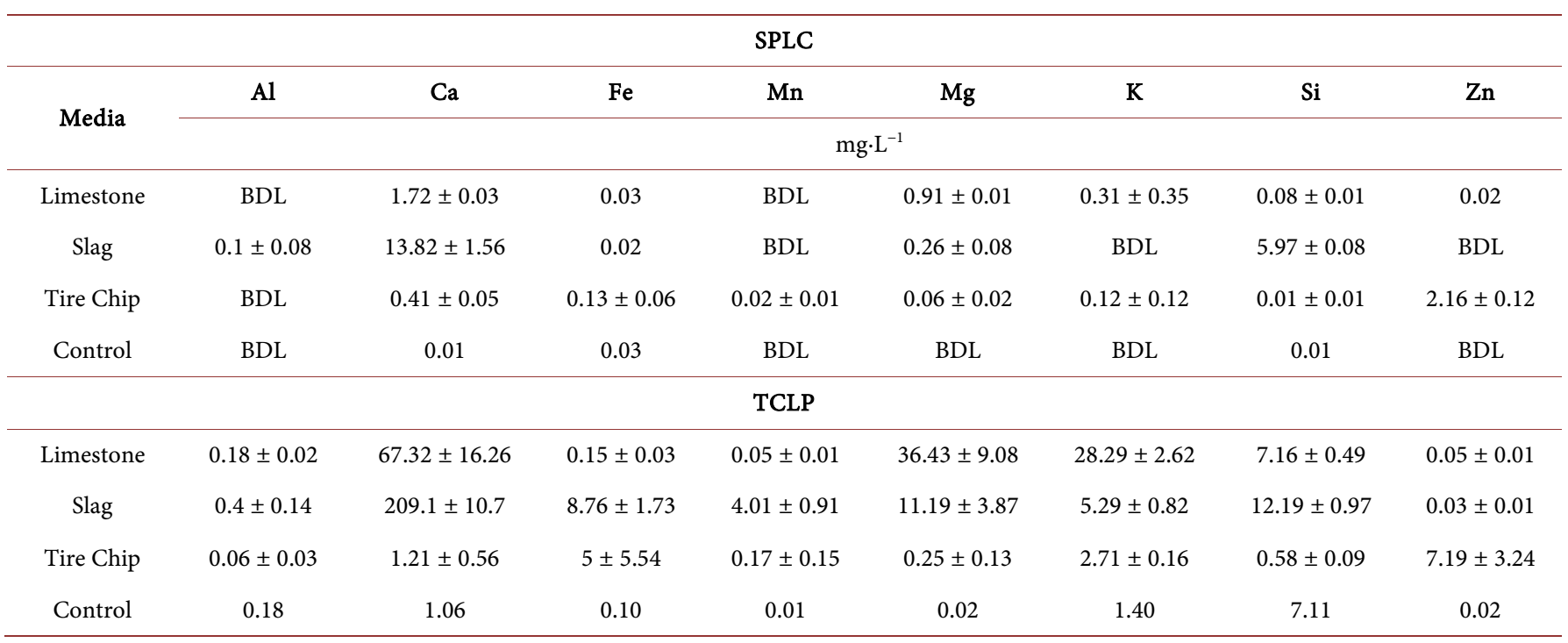

Valued in italic exceed USEPA drinking water threshold; BDL = Below Detection Limit; Analytes BDL: Ag, As, Ba, Be, Cd, Cu, Cr, $\mathrm{Ni}, \mathrm{Pb}, \mathrm{Sb}, \mathrm{Se}, \mathrm{Sn}$, and Ti.

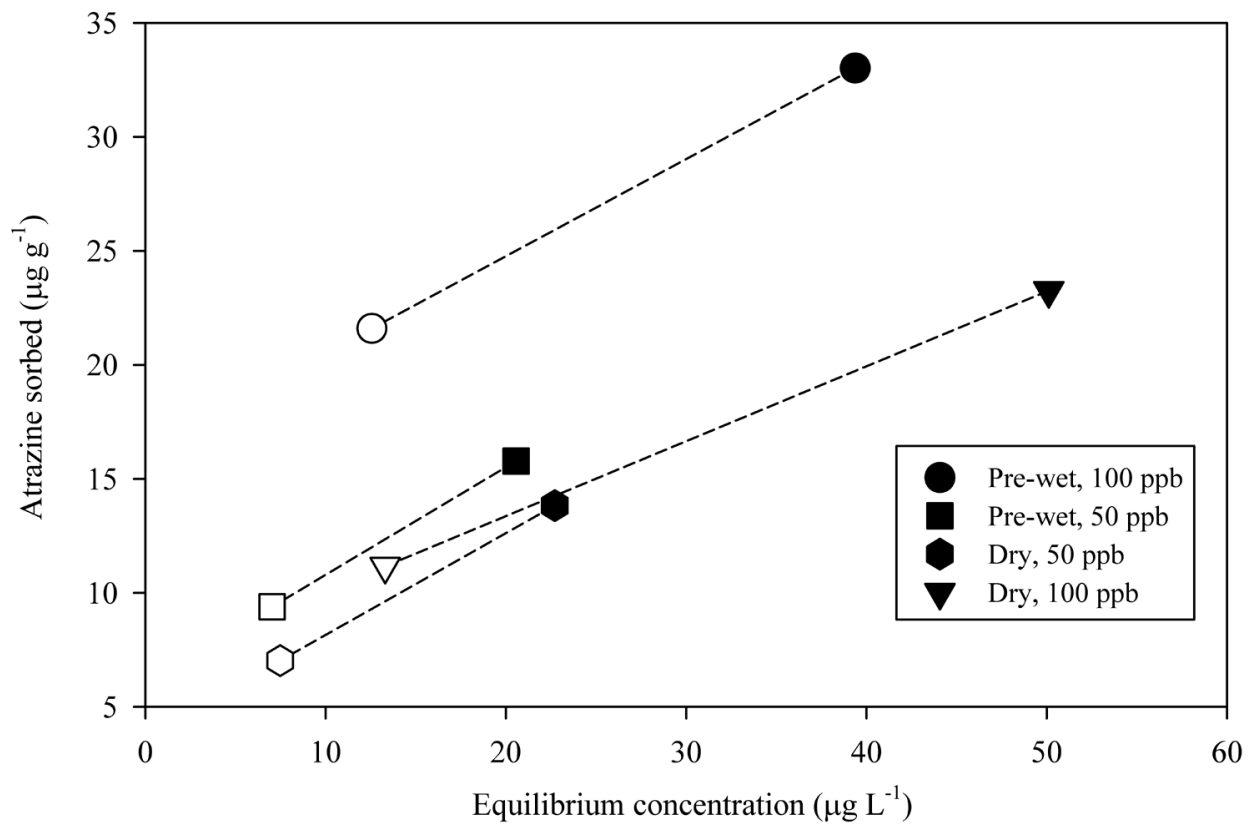

Figure 4. Atrazine sorption and desorption by the dry and pre-wet tire chips using initial atrazine concentrations of 50 and $100 \mu \mathrm{g} \cdot \mathrm{L}^{-1}$. (Filled symbols represent the sorption step, whereas the empty symbols represent the desorption step)

rainfall when the material is sitting in-situ [28], whereas the TCLP test is used to simulate leaching of contaminants under landfill conditions. The SPLC and TCLP values were low or below the detection limit (BDL) of the ICP-EOS instrument. Eight metals (As, $\mathrm{Ba}, \mathrm{Cd}, \mathrm{Cr}, \mathrm{Pb}, \mathrm{Hg}$, Se, and $\mathrm{Ag}$ ) are listed by the U.S. EPA as hazardous, i.e. when concentrations exceed specific concentration levels, e.g. for $\mathrm{Cd}$ and $\mathrm{Se}$ is $1 \mathrm{mg} \cdot \mathrm{L}^{-1}$, and 
for $\mathrm{Ba}$ is $100 \mathrm{mg} \cdot \mathrm{L}^{-1}$ [49]. In our study, we analyzed for seven of these metals (except $\mathrm{Hg})$ and their concentrations were $\mathrm{BDL}\left(<1.5 \mu \mathrm{g} \cdot \mathrm{L}^{-1}\right)$; thus, the above results indicate that under the conditions of the SPLP and TCLP tests, the materials used in this study do not leach metals of environmental concern, and the concentrations do not exceed their hazardous levels.

Of interest, the TCLP extracted the transition metals Fe, Mn, and $\mathrm{Zn}$ with concentrations ranging from 4.01 to $8.76 \mathrm{mg} \cdot \mathrm{L}^{-1}$ from tire chip and steel slag samples (Table 2). Oxidized metal debris protruding in some of the tire chips was observed. Zinc, a component of the vulcanization process in the tire manufacturing [50], has been detected in crumb rubber from recycled tires [51]. The TCLP test for steel slag yielded Fe and Mn $\left(8.76 \pm 1.76\right.$ and $4.01 \pm 0.91 \mathrm{mg} \cdot \mathrm{L}^{-1}$, respectively). Visible incrustations of reddish oxides, likely $\mathrm{Fe}$ and $\mathrm{Mn}$ oxides were observed on the steel slag aggregates. In addition to transition metals, alkali and alkaline earth metals were observed in the limestone and steel slag extracts; where Ca was the highest, 67.3 and $209 \mathrm{mg} \cdot \mathrm{L}^{-1}$, respectively, followed by $\mathrm{Mg}$ and $\mathrm{K}$ (Table 2).

\section{Summary and Conclusions}

In this study, the sorption of atrazine by different sorbents was investigated. The sorbents used in this study were chosen as alternatives or add-on materials to limestone, the current blind inlet bed material, to remove atrazine in solution. The kinetic sorption data indicated that biochar used in this study removed atrazine faster than the tire chips, reaching equilibrium in 6 hours, compared to 30 hours for the tire chips. Furthermore, during a 24-hour sorption/desorption isotherm experiments, biochar was the most efficient material for removing atrazine ( $>99 \%)$, followed by tire chips $(42 \%)$, limestone $(<7 \%)$ and steel slag $(<1 \%)$. The atrazine sorption mechanisms by biochar and tire chips were not investigated; however, hydrophobic interactions and $\mathrm{H}$-bonding were likely mechanisms given the composition of these materials. The tests for leaching metals of environmental concerns from tire chips, steel slag, and limestone were negative, suggesting that these materials may be safe to use under the conditions of the SPLP and TCLP tests.

The information from this study may be useful in improving the effectiveness of conservation practices that require material to sorb pollutants of interest and filter sediments, e.g. blind inlets, filter socks, and rain gardens. Testing of conservation practices constructed using these materials should be conducted to determine if the sorption characteristics observed in the laboratory are operative under field conditions.

\section{Acknowledgements}

The authors would like to thank the staff at the NSERL, with special thanks to students and Janae Bos for the pesticide analysis.

\section{Disclaimer}

USDA is an equal opportunity provider and employer. Mention of trade names or 
commercial products in this publication is solely for the purpose of providing specific information and does not imply recommendation or endorsement by the U.S. Department of Agriculture.

\section{References}

[1] Ginting, D., Moncrief, J.F. and Gupta, S.C. (2000) Runoff, Solids, and Contaminant Losses into Surface Tile Inlets Draining Lacustrine Depressions. Journal of Environmental Quality, 29, 551-560. https://doi.org/10.2134/jeq2000.00472425002900020024x

[2] Smith, D.R. and Livingston, S.J. (2013) Managing Farmed Closed Depressional Areas Using Blind Inlets to Minimize Phosphorus and Nitrogen Losses. Soil Use Management, 29, 94102. https://doi.org/10.1111/j.1475-2743.2012.00441.x

[3] Feyereisen, G.W., Francesconi, W., Smith, D.R., Papiernik, S.K., Krueger, E.S. and Wente, C.D. (2015) Effect of Replacing Surface Inlets with Blind or Gravel Inlets on Sediment and Phosphorus Subsurface Drainage Losses. Journal of Environmental Quality, 44, 594-604. https://doi.org/10.2134/jeq2014.05.0219

[4] Gonzalez, J.M., Smith, D.R., Livingston, S., Warnemuende-Pappas, E. and Zwonitzer, M. (2016) Blind Inlets: Conservation Practices to Reduce Herbicide Losses from Closed Depressional Areas. Journal of Soils and Sediments, 16, 1921-1932. https://doi.org/10.1007/s11368-016-1362-0

[5] RMA (2014) 2013 U.S. Scrap Tire Management Summary. In: I. Rubber Manufacturers Association. http://www.rma.org/publications/scrap-tire-publications/market-reports/

[6] Rowley, A.G., Husband, F.M. and Cunningham, A.B. (1984) Mechanisms of Metal Adsorption from Aqueous Solutions by Waste Tyre Rubber. Water Research, 18, 981-984. https://doi.org/10.1016/0043-1354(84)90248-3

[7] Calisir, F., Roman, F.R., Alamo, L., Perales, O., Arocha, M.A. and Akman, S. (2009) Removal of $\mathrm{Cu}$ (Ii) from Aqueous Solutions by Recycled Tire Rubber. Desalination, 249, 515 518. https://doi.org/10.1016/j.desal.2008.07.029

[8] Kershaw, D.S., Kulik, B.C. and Pamukcu, S. (1997) Ground Rubber: Sorption Media for Ground Water Containing Benzene and O-Xylene. Journal of Geotechnical and Geoenvironmental Engineering, 123, 324-334. https://doi.org/10.1061/(ASCE)1090-0241(1997)123:4(324)

[9] Alamo-Nole, L.A., Perales-Perez, O. and Roman-Velazquez, F.R. (2011) Sorption Study of Toluene and Xylene in Aqueous Solutions by Recycled Tires Crumb Rubber. Journal of Hazardous Materials, 185, 107-111. https://doi.org/10.1016/j.jhazmat.2010.09.003

[10] Alam, J.B., Dikshit, A.K. and Bandyophadyay, M. (2002) Effect of Different Inorganic and Organic Compounds on Sorption of 2,4-D and Atrazine. Journal of Environmental Science and Health, Part B, 37, 541-560. https://doi.org/10.1081/PFC-120015438

[11] Rodgers, B. and Waddell, W. (2013) Chapter 14: Tire Engineering. The Science and Technology of Rubber (Fourth Edition). Academic Press, Boston, 653-695. https://doi.org/10.1016/B978-0-12-394584-6.00014-5

[12] Amari, T., Themelis, N.J. and Wernick, I.K. (1999) Resource Recovery from Used Rubber Tires. Resources Policy, 25, 179-188. https://doi.org/10.1016/S0301-4207(99)00025-2

[13] Hass, A. and Gonzalez, J.M. (2014) Biochar. In: López-Valdez, F. and Fernández-Luqueño, F., Eds., Fertilizers: Components, Uses in Agriculture and Environmental Impacts, Noca Science Publishers, ebook, 95-123.

[14] Hass, A., Gonzalez, J.M., Lima, I.M., Godwin, H.W., Halvorson, J.J. and Boyer, D.G. (2012) 
Chicken Manure Biochar as Liming and Nutrient Source for Acid Appalachian Soil. Journal of Environmental Quality, 41, 1096-1106. https://doi.org/10.2134/jeq2011.0124

[15] Uchimiya, M., Wartelle, L.H. and Boddu, V.M. (2012) Sorption of Triazine and Organophosphorus Pesticides on Soil and Biochar. Journal of Agricultural and Food Chemistry, 60, 2989-2997. https://doi.org/10.1021/jf205110g

[16] Tan, X.F., Liu, Y.G., Zeng, G.M., Wang, X., Hu, X.J., Gu, Y.L. and Yang, Z.Z. (2015) Application of Biochar for the Removal of Pollutants from Aqueous Solutions. Chemosphere, 125, 70-85. https://doi.org/10.1016/j.chemosphere.2014.12.058

[17] Cao, X.D., Ma, L.N., Gao, B. and Harris, W. (2009) Dairy-Manure Derived Biochar Effectively Sorbs Lead and Atrazine. Environmental Science \& Technology, 43, 3285-3291. https://doi.org/10.1021/es803092k

[18] Zheng, W., Guo, M.X., Chow, T., Bennett, D.N. and Rajagopalan, N. (2010) Sorption Properties of Greenwaste Biochar for Two Triazine Pesticides. Journal of Hazardous Materials, 181, 121-126. https://doi.org/10.1016/j.jhazmat.2010.04.103

[19] NASS (2016) Agricultural Chemical Usage. Field Crop Summary. NASS, USDA-National Agricultural Statistics Service, Washington DC.

[20] Stone, W.W., Gilliom, R.J. and Martin, J.D. (2014) An Overview Comparing Results from Two Decades of Monitoring for Pesticides in the Nation's Streams and Rivers, 1992-2001 and 2002-2011. U.S. Geological Survey Scientific Investigations Report 2014-5154, 23 p. https://doi.org/10.3133/sir20145154

[21] Warnemuende, E.A., Patterson, J.P., Smith, D.R. and Huang, C.-H. (2007) Effects of Tilling No-Till Soil on Losses of Atrazine and Glyphosate to Runoff Water under Variable Intensity Simulated Rainfall. Soil and Tillage Research, 95, 19-26. https://doi.org/10.1016/j.still.2006.09.001

[22] Gilliom, R.J. (2007) Pesticides in U.S. Streams and Groundwater. Environmental Science \& Technology, 41, 3408-3414. https://doi.org/10.1021/es072531u

[23] Yildirim, I.Z. and Prezzi, M. (2011) Chemical, Mineralogical, and Morphological Properties of Steel Slag. Advances in Civil Engineering, 2011, Article ID: 463638. https://doi.org/10.1155/2011/463638

[24] Pappas, E.A., Huang, C. and Bucholtz, D.L. (2008) Implications of Sampling Frequency to Herbicide Conservation Effects Assessment. Journal of Soil and Water Conservation, 63, 410-419. https://doi.org/10.2489/jswc.63.6.410

[25] Yuh-Shan, H. (2004) Citation Review of Lagergren Kinetic Rate Equation on Adsorption Reactions. Scientometrics, 59, 171-177. https://doi.org/10.1023/B:SCIE.0000013305.99473.cf

[26] Tseng, R.-L., Wu, P.-H., Wu, F.-C. and Juang, R.-S. (2014) A Convenient Method to Determine Kinetic Parameters of Adsorption Processes by Nonlinear Regression of Pseudo- $n$ th-Order Equation. Chemical Engineering Journal, 237, 153-161. https://doi.org/10.1016/j.cej.2013.10.013

[27] Gonzalez, J.M. and Ukrainczyk, L. (1996) Adsorption and Desorption of Nicosulfuron in Soils. Journal of Environmental Quality, 25, 1186-1192. https://doi.org/10.2134/jeq1996.00472425002500060003x

[28] USEPA (1994) Epa Method 1312: Synthetic Precipitation Leaching Procedure. USEPA, Washington DC.

[29] USEPA (1990) Epa Method 1311: Toxicity Characteristic Leaching Procedure. USEPA, Washington DC.

[30] Rambabu, N., Guzman, C.A., Soltan, J. and Himabindu, V. (2012) Adsorption Characteristics of Atrazine on Granulated Activated Carbon and Carbon Nanotubes. Chemical Engi- 
neering \& Technology, 35, 272-280. https://doi.org/10.1002/ceat.201100376

[31] Gupta, V.K., Gupta, B., Rastogi, A., Agarwal, S. and Nayak, A. (2011) Pesticides Removal from Waste Water by Activated Carbon Prepared from Waste Rubber Tire. Water Research, 45, 4047-4055. https://doi.org/10.1016/j.watres.2011.05.016

[32] Deng, H., Yu, H.M., Chen, M. and Ge, C.J. (2014) Sorption of Atrazine in Tropical Soil by Biochar Prepared from Cassava Waste. BioResources, 9, 6627-6643. https://doi.org/10.15376/biores.9.4.6627-6643

[33] Alam, J.B., Dikshit, A.K. and Bandyopadhyay, M. (2007) Kinetic Study of Sorption of 2,4-D and Atrazine on Rubber Granules. Journal of Dispersion Science and Technology, 28, 511517. https://doi.org/10.1080/01932690701277021

[34] Alam, J.B., Dikshit, A.K. and Bandyopadhyay, M. (2004) Sorption and Desorption of 2,4-D and Atrazine from Water Environment by Waste Tyre Rubber Granules and Its Management. Global Nest Journal, 6, 105-115.

[35] Zhao, X.C., Ouyang, W., Hao, F.H., Lin, C.Y., Wang, F.L., Han, S. and Geng, X.J. (2013) Properties Comparison of Biochars from Corn Straw with Different Pretreatment and Sorption Behaviour of Atrazine. Bioresource Technology, 147, 338-344. https://doi.org/10.1016/j.biortech.2013.08.042

[36] Hao, F.H., Zhao, X.C., Ouyang, W., Lin, C.Y., Chen, S.Y., Shan, Y.S. and Lai, X.H. (2013) Molecular Structure of Corncob-Derived Biochars and the Mechanism of Atrazine Sorption. Agronomy Journal, 105, 773-782. https://doi.org/10.2134/agronj2012.0311

[37] Krull, E.S., Baldock, J.A., Skjemstad, J.O. and Smernik, R.J. (2009) Characteristics of Biochar: Organo-Chemical Properties. In: Lehmann, J. and Joseph, S., Eds., Biochar for Environmental Management. Science and Technology, Earthscan, London.

[38] Amonette, J.E. and Joseph, S. (2009) Characteristics of Biochar: Microchemical Properties. In: Lehmann, J. and Joseph, S., Eds., Biochar for Environmental Management. Science and Technology, Earthscan, London, 33-52.

[39] Xiao, F. and Pignatello, J.J. (2015) Interactions of Triazine Herbicides with Biochar: Steric and Electronic Effects. Water Research, 80, 179-188.

https://doi.org/10.1016/j.watres.2015.04.040

[40] Laird, D.A. and Koskinen, W.C. (2008) Chapter 21-Triazine Soil Interactions. In: Homer, M.L., Janis, E.M. and Burnside, O.C., Eds., The Triazine Herbicides, Elsevier, San Diego, 275-299.

[41] Alam, J., Dikshit, A. and Bandyopadhyay, M. (2000) Efficacy of Adsorbents for 2, 4-D and Atrazine Removal from Water Environment. Global Nest Journal, 2, 139-148.

[42] Janniche, G.S., Mouvet, C. and Albrechtsen, H.-J. (2010) Acetochlor Sorption and Degradation in Limestone Subsurface and Aquifers. Pest Management Science, 66, 1287-1297. https://doi.org/10.1002/ps.2011

[43] Chefetz, B., Bilkis, Y.I. and Polubesova, T. (2004) Sorption-Desorption Behavior of Triazine and Phenylurea Herbicides in Kishon River Sediments. Water Research, 38, 4383-4394. https://doi.org/10.1016/j.watres.2004.08.023

[44] Kasozi, G.N., Nkedi-Kizza, P., Li, Y. and Zimmerman, A.R. (2012) Sorption of Atrazine and Ametryn by Carbonatic and Non-Carbonatic Soils of Varied Origin. Environmental Pollution, 169, 12-19. https://doi.org/10.1016/j.envpol.2012.05.002

[45] Borggaard, O.K. and Streibig, J.C. (1988) Atrazine Adsorption by Some Soil Samples in Relation to Their Constituents. Acta Agriculturae Scandinavica, 38, 293-301.

[46] Soni, N., Leon, R.G., Erickson, J.E., Ferrell, J.A. and Silveira, M.L. (2015) Biochar Decreases Atrazine and Pendimethalin Preemergence Herbicidal Activity. Weed Technology, 29, 359- 
366. https://doi.org/10.1614/WT-D-14-00142.1

[47] Pignatello, J.J. and Xing, B. (1995) Mechanisms of Slow Sorption of Organic Chemicals to Natural Particles. Environmental Science \& Technology, 30, 1-11.

https://doi.org/10.1021/es940683g

[48] Bachmann, H.J., Bucheli, T.D., Dieguez-Alonso, A., Fabbri, D., Knicker, H., Schmidt, H.-P., et al. (2016) Toward the Standardization of Biochar Analysis: The COST Action TD1107 Interlaboratory Comparison. Journal of Agricultural and Food Chemistry, 64, 513-527. https://doi.org/10.1021/acs.jafc.5b05055

[49] USEPA (2011) Toxicity Characteristic (40 Cfr 261.24). USEPA, United States Environmental Protection Agency, Washington DC.

[50] Clark, S.K. (1981) Mechanics of Pneumatic Tires. US Department of Transportation, National Highway Traffic Safety Administration.

[51] Mattina, M.I., Isleyen, M., Berger, W. and Ozdemir, S. (2007) Examination of Crumb Rubber Produced from Recycled Tires. The Connecticut Agricultural Experiment Station, New Haven.

Submit or recommend next manuscript to SCIRP and we will provide best service for you:

Accepting pre-submission inquiries through Email, Facebook, LinkedIn, Twitter, etc.

A wide selection of journals (inclusive of 9 subjects, more than 200 journals)

Providing 24-hour high-quality service

User-friendly online submission system

Fair and swift peer-review system

Efficient typesetting and proofreading procedure

Display of the result of downloads and visits, as well as the number of cited articles

Maximum dissemination of your research work

Submit your manuscript at: http://papersubmission.scirp.org/

Or contact jwarp@scirp.org 